\title{
Comparative Study of the Cultural Effective Factors on Women's Total Fertility Rate in Fertile Age
}

\author{
Sohyla Reshadat, ${ }^{1}$ Alireza Zanganeh, ${ }^{2,}$ Shahram Saeidi, ${ }^{2}$ S. Ramin Ghasemi, ${ }^{2}$ Nader Rajabi-Gilan, ${ }^{2}$ Ali \\ Karbasi, ${ }^{2}$ and Raziyeh Teymouri ${ }^{3}$ \\ ${ }^{1}$ Center of Excellence for Community Oriented Medicine Education, Kermanshah University of Medical Sciences, Kermanshah, IR Iran \\ ${ }^{2}$ Social Development and Health Promotion Research Center, Kermanshah University of Medical Sciences, Kermanshah, IR Iran \\ ${ }^{3}$ Geography and Urban Planning, University of Tabriz, Tabriz, IR Iran \\ "Corresponding author: Alireza Zanganeh, Social Development and Health Promotion Research Center, Kermanshah University of Medical Sciences, Kermanshah, IR Iran. \\ E-mail: ali.zangeneh88@gmail.com
}

Received 2015 January 5; Accepted 2015 April 6.

\begin{abstract}
Background: Fertility is one of the important elements of population growth.

Objectives: The aim of this study was comparative surveying of the cultural effective factors on TFR (total fertility rate) in Kermanshah in 1996, 2006 and 2011.

Materials and Methods: In this quantitative study, data were prepared from Iran statistics center, health center and registration center. Structural equation models were used for modeling in AMOS software.

Results: Men's average marriage age in 1996 and women schooling rate in 2006 and 2011, coefficients was equals $0.05,0.08$ and 0.19 respectively, have had the highest effects on fertility decrease.

Conclusions: In this study women schooling rate had the highest effect on fertility decrease.
\end{abstract}

Keywords: Fertility, Cultural Characteristics, Women

\section{Background}

Sudden growth of population caused important demographic problems in the half past century and most of the developed countries confronted with population decline trends in 21th century [1]. So, fertility decrease had everlasting effect on world population [2]. Fertility is influenced by lots of factors such as economic, social and cultural factors (such as: family income, father's job, women who work overtime in general places, women schooling rate, women illiteracy rates, urbanization and etc.) [3]. Also women fertility is affected by literacy, health, income, residency place, marriage, family aspect and etc. [4].

Education and employment change the women attitudes toward fertility and challenge for reaching these goals has led marriage age to be increased [1]. Nowadays, marriage institutions have realized the role of culture in decrease of fertility [5]. Cultural Revolution by affecting on urbanization extension and education has decreased the fertility rate [6]. In terms of the fertility changes in Iran, Abbasi-Shavazi and McDonald suggested that increasing of the urbanization level, women education level and women marriage age -because of job competition after revolution and enhancement of the women social and economic status- are the main factors of the decrease of fer- tility in Iran [7].

\section{Objectives}

Because of effects of population changes in societies and benefits of identification of the effective cultural factors, this research was done by aim of comparative surveying of the cultural effective factors on total fertility rate (TFR) in Kermanshah in 1996, 2006 and 2011.

\section{Materials and Methods}

This quantitative research designed with correlation based on structural equations. For explaining the relationship of model causative variances, the data was prepared by public census and Iran housing, health statistics, medical sciences organization and registration center of Kermanshah in 1996, 2006 and 2011.

The data was based on the public, housing census, determination of the numbers of population in each geographic unit, identification of demographical and household characteristics according to article "Four of Iran statistical center law" by permission of board of ministers based on defined time interval. After public housing census in 2006, the time interval of public housing census has 
been declined from ten years to five years [8]. So, we used previous and new census policies in this research. Indexing was begun by using information bank data in ArcGIS and ArcView software. The data was used for calculating TFR and then path analysis was carried out in AMOS for analyzing the effect of variances. Structural equation modeling is a multivariate technique that by using it, researchers can assess some relations between independent and dependent variables simultaneously. The effective cultural factors include: women schooling rate, the rate of society employment to education, society illiteracy rate, women literacy rate, urbanization rate, women's average marriage age, men's average marriage age, society literacy rate, and women illiteracy rate.

One of the indictors that can be used for measuring fertility is total fertility rate which can be calculated as follow:

$\mathrm{MFR}=\frac{B}{\operatorname{Fm}(15-49)} \times 100$

MFR = martial fertility rate; $\mathrm{B}=$ alive babies in a year; Fm $(15-49)=$ married women $(15-49$ years old $) /$ year

TotalFertilityRate $(\mathrm{TFR})=\frac{\mathrm{MFR}}{1000} \times 35$

\section{Results}

Martial fertility rate (MFR) in Kermanshah was 71.42 in 1996, 53.14 in 2006 and 54.30 in 2011.

Total fertility rate (TFR) was 2.5 in 1996, 1.86 in 2006 and 1.72 in 2011.

The results showed that 9 factor were important in explaining fertility changes in the study period. These factors presented in Table 1.

In 1996, the path diagram is based on causal dependence and the effective factor is men's average marriage age. Women schooling rate, women illiteracy rate, women literacy rate, women's average marriage age and education level of society were effective on TFR. But the degree of urbanization, society illiteracy rate and the rate of society employment to education were ineffective on fertility.

In 2006, the path diagram is done based on the causal dependence and the effective factor. Women schooling rate, women literacy rate, women's average marriage age, men's average marriage age, society illiteracy rate, urbanization degree, society literacy rate and women illiteracy rate were effective on TFR. But degree of urbanization, the rate of society employment to education and women illiteracy rate were ineffective on TFR.

According to the path analysis in 2011, we see that $\chi^{2}=$ 35.240 and $\mathrm{fd}=23$ and $\mathrm{P}=0.049$ which $\mathrm{P}$ value is less than 0.05 and it depicts proper fitness of the regression model.
In this regard, comparative fit index (CFI), normed fit index (NFI), root mean square error of approximation (RMSEA), root mean score residual (RMR), goodness of fit index (GFI) and adjusted goodness of fit index (AGFI) depict acceptable fitness (Table 2).

If we urbanization degree by $\mathrm{X} 1$, men's average marriage age by $\mathrm{X} 2$, women's average marriage age by $\mathrm{X} 3$, women schooling rate by $\mathrm{X} 4$, rate of the society employment to education by X5, women literacy by X6, society literacy by $\mathrm{X} 7$, women illiteracy rate by $\mathrm{X} 8$, society illiteracy rate by X9, TFR by $Y$ and regression constant coefficient by A following structural equation is obtained:

$$
\mathrm{Y}=\mathrm{A}+0.03 \mathrm{X} 1+0.02 \mathrm{X} 2+0.02 \mathrm{X} 3+0.019 \mathrm{X} 4+0.012 \mathrm{X} 5
$$

$+0.04 \mathrm{X} 6+0.02 \mathrm{X} 7+0.01 \mathrm{X} 8+0.07 \mathrm{X} 9$

Path diagram is done based on two basic assumptions which the first one is causal dependence and the second one is casual sequence and the most effective factor is women schooling rate. The rate of society employment to education level, society illiteracy rate, women literacy rate, degree of urbanization, women's average marriage age, men's average marriage age, society literacy rate and women literacy rate were also effective on TFR (Figure 1).

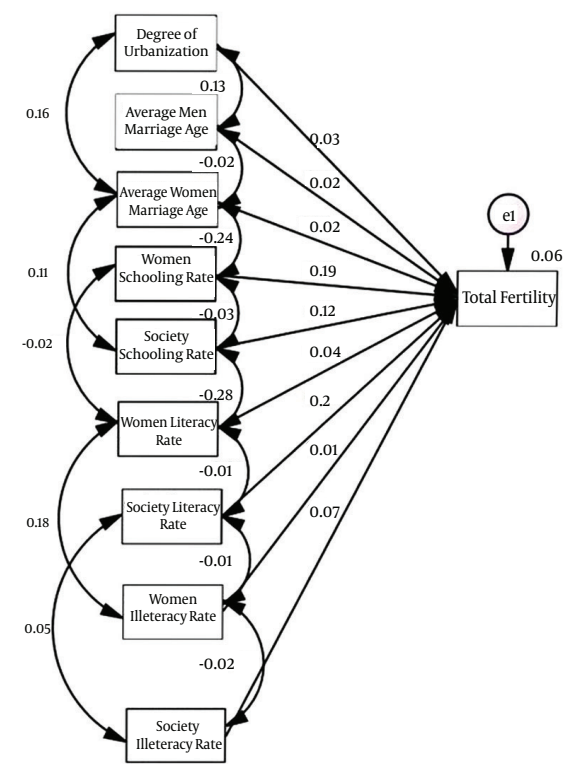

Figure 1. Path Diagram of the effects of the Major Cultural Factors on Total Fertility Rate (TFR) in Kermanshah in 2011

\section{Discussion}

This study showed that TFR have had a descending trend in the study period and women schooling rate have 
Table 1. Kermanshah Cultural Indictors in 2011

\begin{tabular}{|c|c|c|c|}
\hline \multirow[t]{2}{*}{ Indictor } & \multicolumn{3}{|c|}{ Year } \\
\hline & 1996 & 2006 & 2011 \\
\hline Literacy rate & 79.96 & 87.57 & 87.03 \\
\hline Illiteracy rate & 20.03 & 12.42 & 12.96 \\
\hline Society schooling rate & 37.70 & 22.95 & 25.42 \\
\hline Women literacy rate & 75.20 & 83.80 & 83.46 \\
\hline Women illiteracy rate & 24.79 & 16.19 & 15.99 \\
\hline Women schooling rate & 14.69 & 23.15 & 25.14 \\
\hline Urbanization rate & 23.46 & 42.28 & 62.82 \\
\hline Women's average marriage & 23.60 & 23.60 & 23.2 \\
\hline Men's average marriage & 25.60 & 26.60 & 26.8 \\
\hline
\end{tabular}

Table 2. Model Fitness Indictors ${ }^{\mathrm{a}}$

\begin{tabular}{lcc}
\hline Fitness Index & PValue & Standard Value \\
\hline CFI & 0.961 & Standard values $>$ \\
NFI & 0.932 & 0.9 \\
RMSEA & 0.092 & $<0.1$ are acceptable and if it is $<0.05$, it will be very optimal and if it ranges $0.05-0.08$, it will be optimal \\
RMR & 0.008 & $<0.05$ are optimal \\
GFI & 0.951 & $>0.9$ are acceptable (some propose $>0.8)$ \\
AGFI & 0.841 & $>0.9$ are acceptable (some propose $>0.8)$ \\
\hline
\end{tabular}

${ }^{a}$ Abbreviations: AGFI, adjusted goodness of fit index; CFI: comparative fit index; GFI, goodness of fit index; NFI, normed fit index; RMSEA: root mean square error of approximation; RMR, root mean score residual.

had the highest effect on fertility decrease among the effective factors.

TFR in 1996, 2006 and 2011 were 2.5, 1.86 and 1.72 respectively. In comparison at this time period, the TFR for Iran were 2.95, 1.99 and 1.88; for Germany were 1.3, 1.33 and 1.41; for Turkey were 2.72, 2.3 and 2.15; and for Iraq were 3.36, 4.18, 3.67 [9].

In the path analysis of 2011, there were 9 affecting factors on TFR that the most important factors were "women schooling rate", "women illiteracy rate" and "urbanization". So during the study period, increasing in women education had reduced the total fertility. Kalantari et al. studies showed that women education was of the effective factor on the fertility decline (more education level, less fertility) [10]. Hezarjaribi and Abbaspour also suggested an inverse relationship between women's education and fertility rate [11]. The impact of women's education on fertility was high in India [12] and increase of education was effective on fertility in China [13] that confirms our findings. Increase of the education level, improves the knowledge, possibility of finding job, health knowledge such as con- traceptive methods and social participation of individuals, which can reduce fertility in these people.

In the study period, by reduction of illiteracy, total fertility has also been declined which it is consistent to Sadeghi's research [14]. This similarity implies that illiteracy and lack of knowledge can continue in next generations by increasing of fertility in illiterate families.

Also, urbanization coefficient had a big impact on total fertility rate in the study period. Similarly in China urbanization has been effective in fertility decline [14]. Also urbanization is an important factor in fertility decline in Africa [15] that these findings are consistent with the results of our study. Urbanization, by presenting opportunities such as education, employment and more social relations for women, can increase their knowledge, change their priorities and therefore decrease their fertility behaviors. So, it can be concluded that literacy and education not only determine efficiency but also shift in education and literacy can effect on demographic issues like fertility. Educational polices can change fertility rate. 


\section{Acknowledgments}

The researchers are extremely grateful to the Kermanshah University of Medical Sciences for financial support (Project code: 92445).

\section{Footnotes}

Authors' Contribution: All authors had equal role in design, work, statistical analysis and manuscript writing.

Funding/Support: Kermanshah University of Medical Sciences, social development and health promotion research center.

\section{References}

1. Chen YH. Trends in low fertility and policy responses in Taiwan. Jpn J Popul. 2012;10(1):78-88.

2. McDonald P. Very low fertility: Consequences, causes and policy approaches. Jpn J Popul. 2008;6(1):19-23.

3. Ghobadi S. Study of women referred to health centers -the number one city of Zanjan- on some family planning methods. J Zanjan Univ Med Sci. 2001;9(34):41-6.

4. Do QT, Levchenko AA, Raddatz C, editors. Comparative advantage, international trade, and fertility. Proceeding of the Research Seminar in International Economics. 2012; Michigan. University of Michigan.
5. Suzuki T. Low fertility and governmental intervention in Japan and Korea.Jpn J Popul. 2012;10(1):60-77.

6. Shiri T, Bidariyan S. Study of demographic and economic factors af fecting fertility among women 15-49 years in education organization. Soc Sci Res. 2010;3(3):93-107.

7. Abbasi-Shavazi MJ, McDonald P. Fertility decline in the Islamic Republic of Iran: 1972-2000. Asian Popul Stud. 2006;2(3):217-37.

8. Statistical Center of Iran . Implementation of the 2011 Iranian Population and Housing Census In Autumn (24 October-13 November 2011) 2011. Available from: http://amar.org.ir/english/Census-2011.

9. Geoba S. The world: Total fertility rate (2014).

10. Kalantari S, Beikmohammadi H, Zare Shahabadi A. Demographic factors affecting fertility of women in Yazd in 2004. J Women Res. 2005;3(2):137-56.

11. Hezarjaribi J, Abbaspour R. The impact of socioeconomic factors on women fertility rates (the case; Tabriz city). J Soc Res. 2010;13(6):13953.

12. Bhat PN, Zavier AJ. Fertility decline and gender bias in northern India. Demography. 2003;40(4):637-57. [PubMed:14686135].

13. Hussain A. Demographic transition in China and its implications World Dev. 2002;30(10):1823-34.

14. Sadeghi JM. Socio-economic factors affected the recent fertility decline in Iran and some comparison with other MENA countries. ERF 7th annual conference, ERF region: trends and prospects for growth and human development, economic research forum for the Arab Countries, Iran and Turkey (ERF), Amman, Jordan. .

15. Murthi M. Fertility change in Asia and Africa. World Dev 2002;30(10):1769-78. doi: 10.1016/S0305-750X(02)00062-1. 